Supporting information for

\title{
Modeling semi-batch vinyl acetate polymerization processes
}

Andreas Feuerpfeil ${ }^{1}$, Marco Drache ${ }^{1}$, Laura-Alice Jantke ${ }^{2}$, Timo Melchin ${ }^{2}$, Jessica RodríguezFernánde ${ }^{2}$, Sabine Beuermann ${ }^{1 *}$

${ }^{1}$ Clausthal University of Technology, Institute of Technical Chemistry, Arnold-SommerfeldStraße 4, 38678 Clausthal-Zellerfeld, Germany

${ }^{2}$ Wacker Chemie AG, Johannes-Hess-Str. 24, 84489 Burghausen, Germany

*sabine.beuermann@tu-clausthal.de

Table S1: Physical properties of the substances in the reaction mixture

\begin{tabular}{|l|l|l|}
\hline substance & $\begin{array}{l}\text { molar mass } \\
\mathrm{g} \mathrm{mol}^{-1}\end{array}$ & $\begin{array}{l}\text { density } \\
/ \mathrm{kg} \mathrm{m}^{3}\end{array}$ \\
\hline vinyl acetate $^{1}$ & 86.09 & $\rho=959.3-1.34 * T$ (in $\left.{ }^{\circ} \mathrm{C}\right)$ \\
\hline methanol $^{2}$ & 32.04 & $\begin{array}{l}\rho=\frac{A}{1+\left(1-\frac{T}{C}\right)^{D}} \\
B\end{array}$ \\
& & $\begin{array}{l}A=54.566, B=0.233211, C=513.16, D=0.20887 \\
T \text { in } \mathrm{K}\end{array}$ \\
\hline tert-butyl peroxypivalate $^{3}$ & 174.2 & - \\
\hline poly(vinyl acetate) $)^{1}$ & - & $\rho=1209.4-0.49 * T\left(\right.$ in $\left.{ }^{\circ} \mathrm{C}\right)$ \\
\hline
\end{tabular}




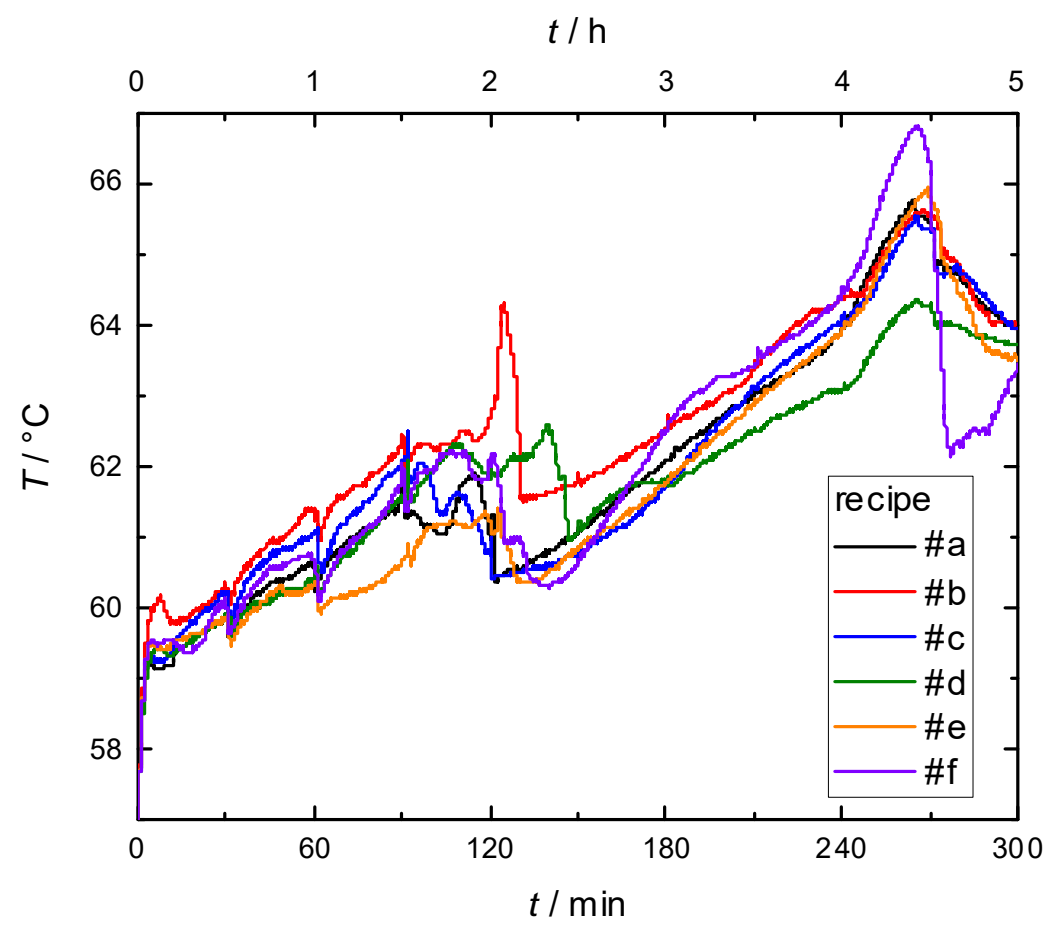

Figure S1: Temperature profiles for the recipes given in Table 1 of the main text. The temperatures are coupled with the actual composition of the reaction mixtures 


\section{Determination of transfer coefficients based on literature data}

The transfer constants and the propagation rate coefficient of macromonomers with terminal double bonds are taken from the literature. In Figures S2, S3 and S4 the Arrhenius diagrams are shown for the transfer rate coefficients, converted from the transfer constants in the original publications. For the transfer to polymer reactions the difference in the activation energies of the transfer and the propagation reaction was given by Nozakura et al. ${ }^{4}$ To determine the pre-exponential factors the given activation energies were converted into slopes in the linear Arrhenius diagram (Figure S2 and S3). In Figure S5 the Arrhenius diagram of the propagation rate coefficient of a macromonomer is illustrated. The Arrhenius diagram shown is calculated with the reactivity factor $K$ of the original publication.

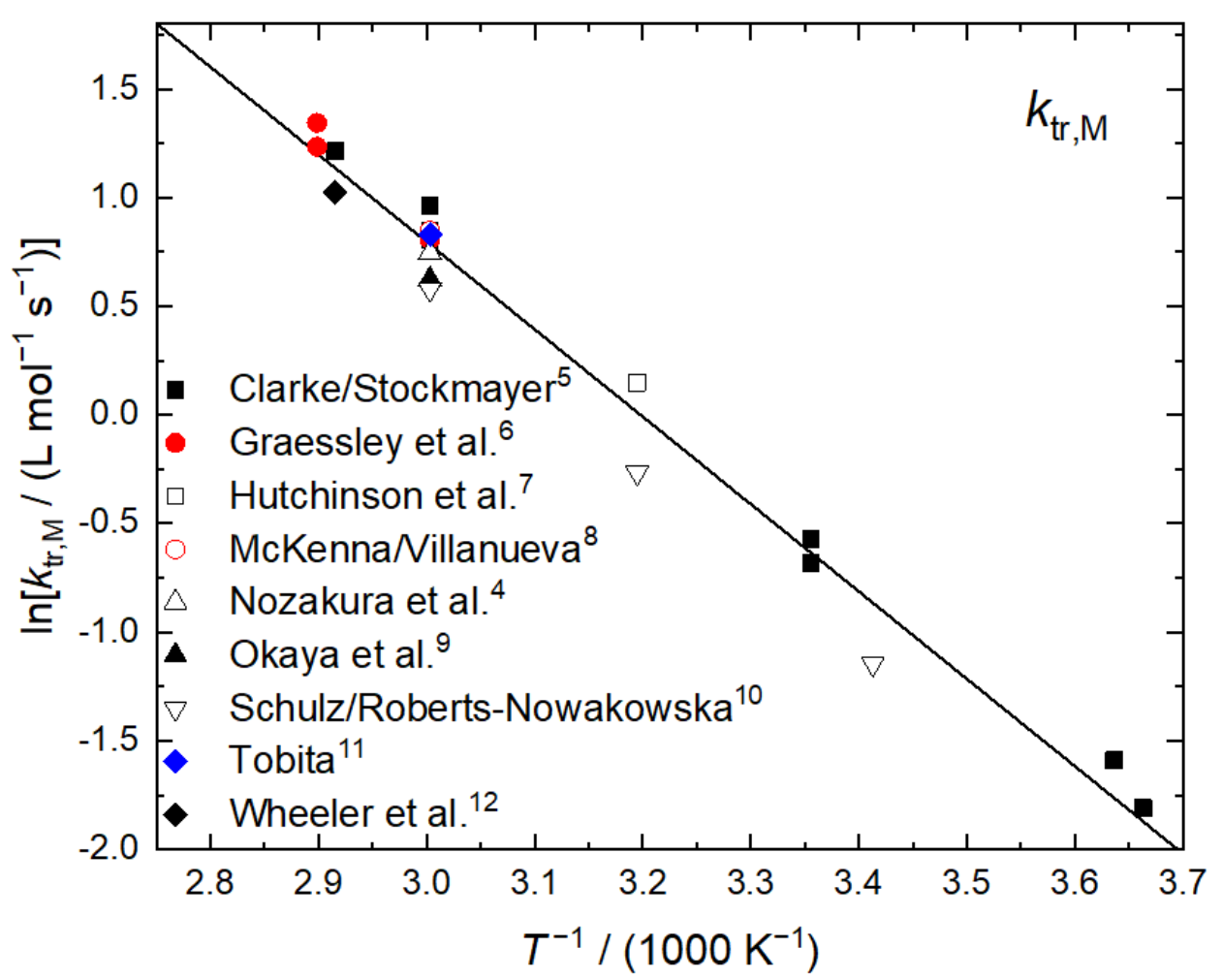

Figure S2: Arrhenius diagram of the transfer to the monomer rate coefficient. Pre-exponential factor $A=3.85 \cdot 10^{5} \mathrm{~L} \mathrm{~mol}^{-1} \mathrm{~s}^{-1}$. Activation energy $E_{\mathrm{a}}=33.4 \mathrm{~kJ} \mathrm{~mol}^{-1}$. ${ }^{4-12}$ 


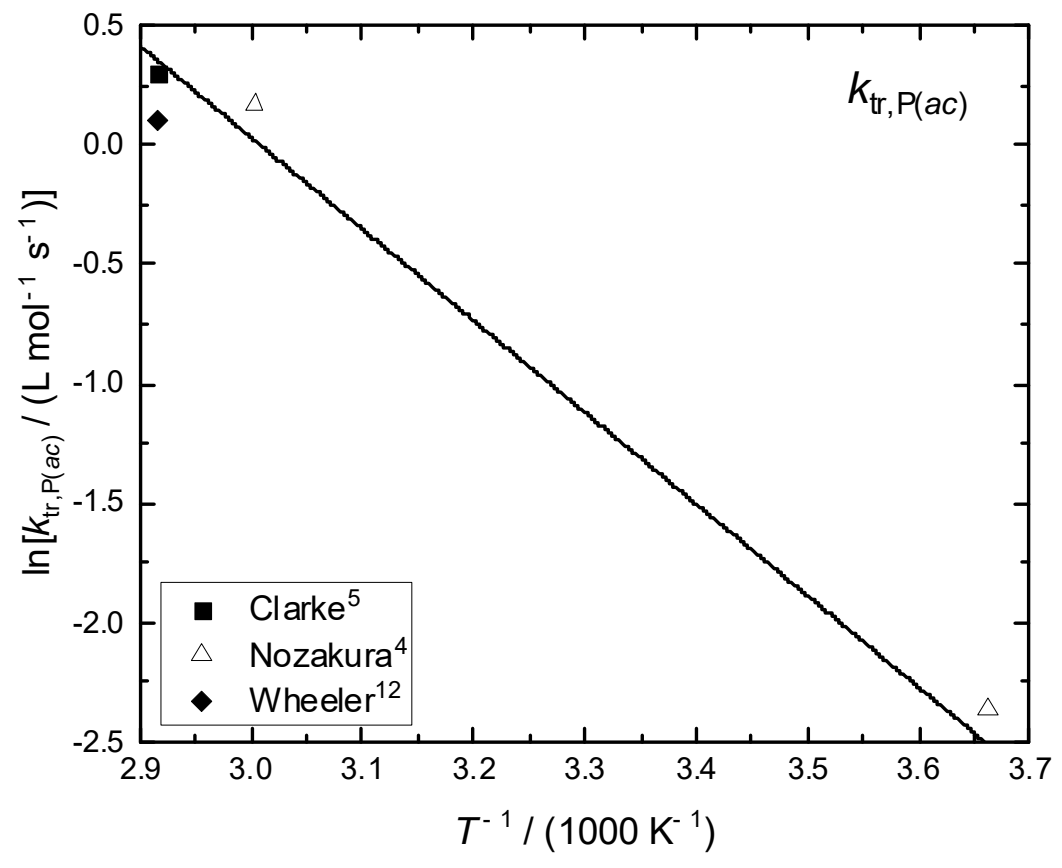

Figure S3: Arrhenius diagram of the transfer to polymer on the acetate group rate coefficient. Preexponential factor $A=1.03 \cdot 10^{5} \mathrm{~L} \mathrm{~mol}^{-1} \mathrm{~s}^{-1}$. Activation energy $E_{\mathrm{a}}=31.9 \mathrm{~kJ} \mathrm{~mol}^{-1}$.,5,12 


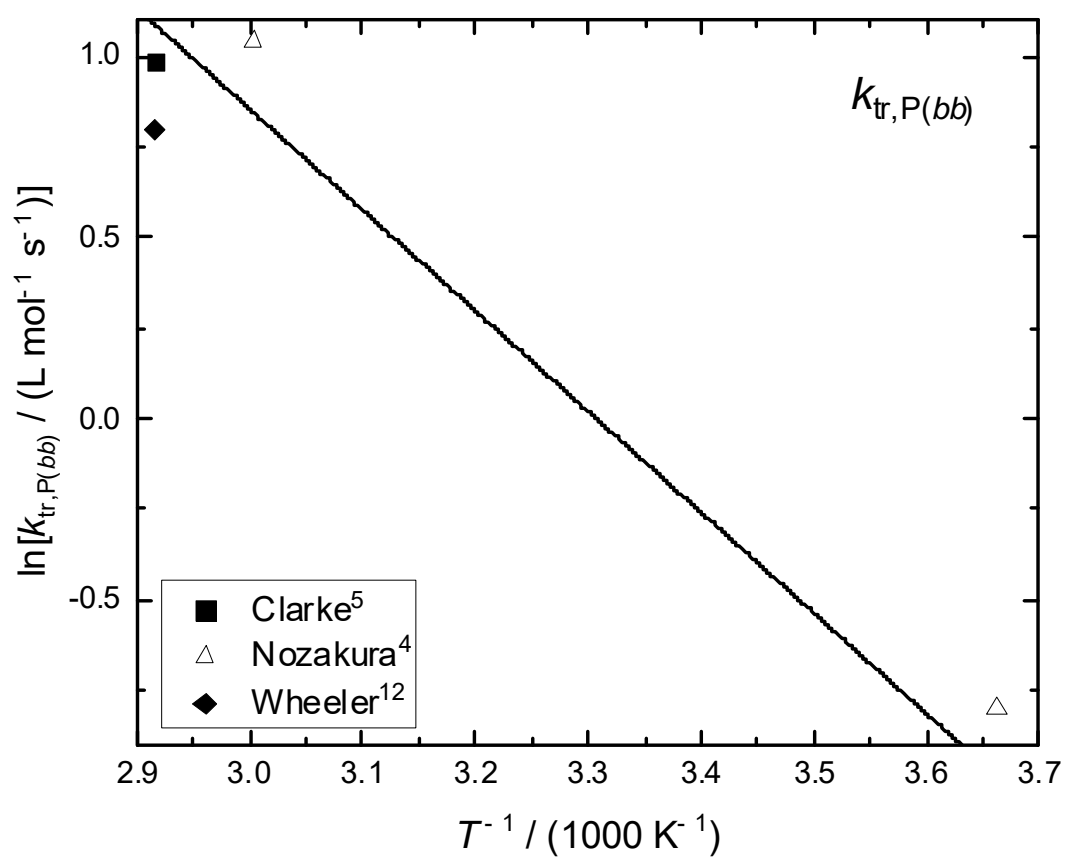

Figure S4: Arrhenius diagram of the transfer to polymer on the backbone rate coefficient. Preexponential factor $A=9.82 \cdot 10^{3} \mathrm{~L} \mathrm{~mol}^{-1} \mathrm{~s}^{-1}$. Activation energy $E_{\mathrm{a}}=23.1 \mathrm{~kJ} \mathrm{~mol}^{-1}$.,5,12 


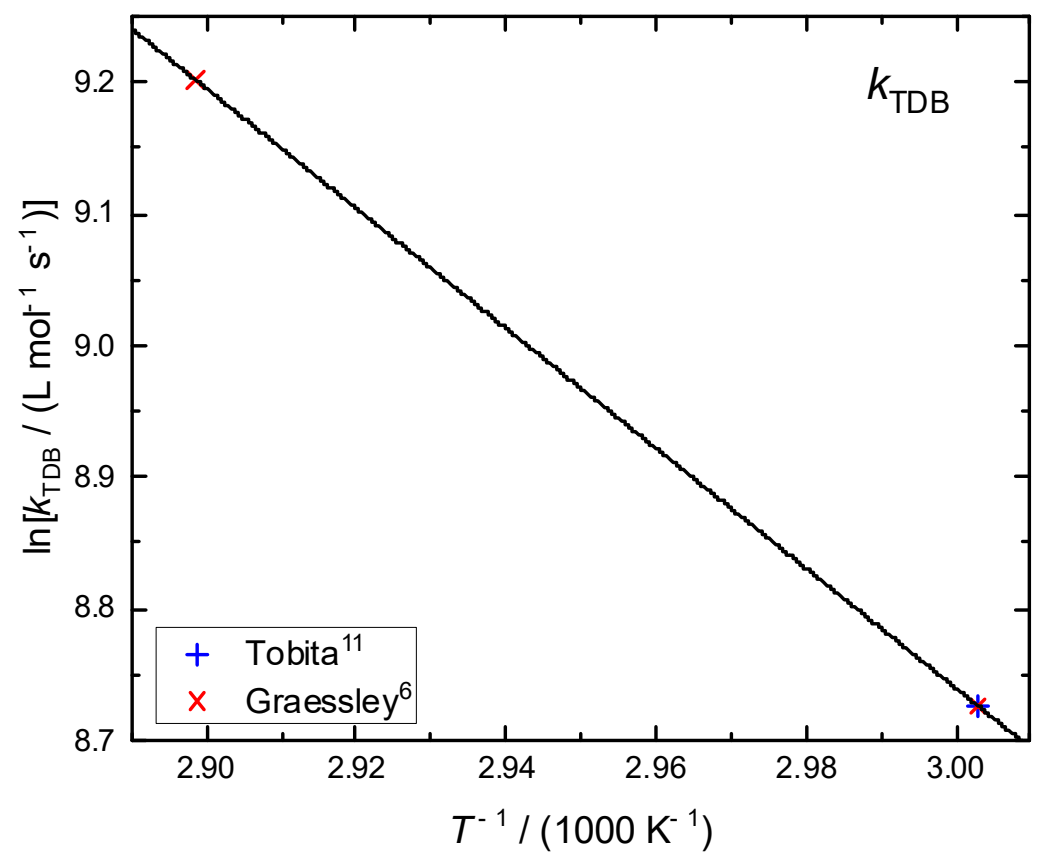

Figure S5: Arrhenius diagram of the macromonomer propagation rate coefficient. Pre-exponential factor $A=5.39 \cdot 10^{9} \mathrm{~L} \mathrm{~mol}^{-1} \mathrm{~s}^{-1}$, activation energy $E_{\mathrm{a}}=37.9 \mathrm{~kJ} \mathrm{~mol}^{-1}{ }^{6,11}$ 
Comparison of equation (S1, 4 of the main text) and (S3, 6 of the main text) for the case of a low $P_{2}$ or a high $P_{3}$ value

In the case of a low $P_{2}$ or a high $P_{3}$ value the $k_{\mathrm{t}}^{1,1}$ value at zero solids content is noticeably lowered. To prevent this behavior, equation (S3) was introduced. The comparison of equation (S1) and (S3) (see below) is shown in Figure S6: the orange and the solid black curve were calculated with the same parameter values, but equation (S1) (orange) starts below the normalized $k_{\mathrm{t}}{ }^{1,1}$-value, while equation (S3) starts as expected at 1.

$$
\begin{aligned}
& k_{\mathrm{t}}^{1,1}=k_{\mathrm{t}}^{1,1}\left(X^{\prime}=0\right) \cdot \frac{1-P_{1} \cdot X^{\prime}}{1+\exp \left(\frac{X^{\prime}-P_{2}}{P_{3}}\right)} \\
& P_{0}=1+\exp \left(\frac{-P_{2}}{P_{3}}\right) \\
& k_{\mathrm{t}}^{1,1}=k_{\mathrm{t}}^{1,1}\left(X^{\prime}=0\right) \frac{P_{0}-P_{1} \cdot X^{\prime}}{1+\exp \left(\frac{X^{\prime}-P_{2}}{P_{3}}\right)}=k_{\mathrm{t}}^{1,1}\left(X^{\prime}=0\right) \frac{1+\exp \left(\frac{-P_{2}}{P_{3}}\right)-P_{1} \cdot X^{\prime}}{1+\exp \left(\frac{X^{\prime}-P_{2}}{P_{3}}\right)}
\end{aligned}
$$

The influence of $P_{1}$ is illustrated with the black and the red curves. The black curves have the same values of the parameters, but for the dashed curve $P_{1}$ was set to $P_{1}=0$. The red dotted curve matches the black solid curve and demonstrates that the shape of the black solid curve is not determined by $P_{1}$. 


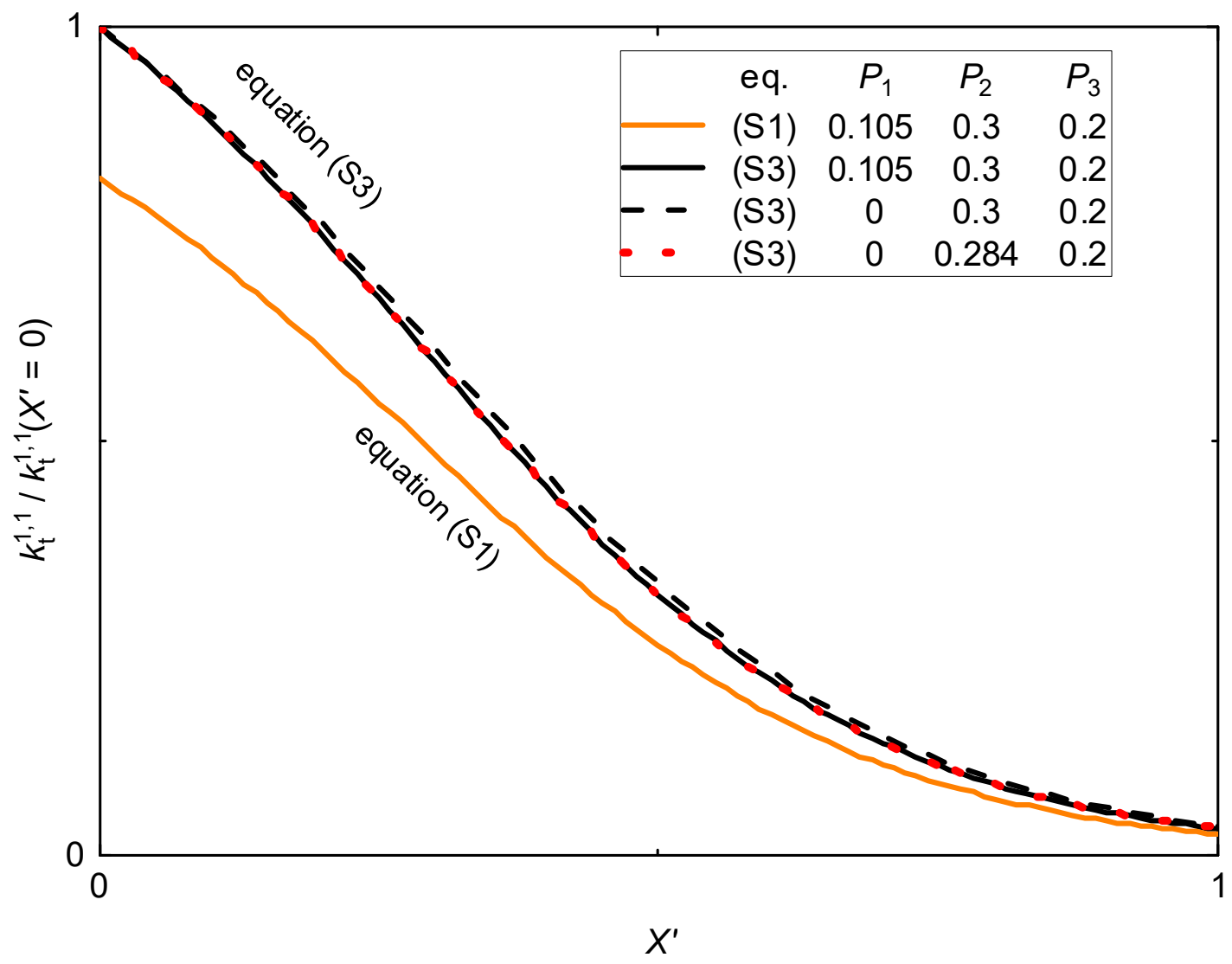

Figure S6: Variation of $k_{\mathrm{t}}{ }^{1,1} / k_{\mathrm{t}}{ }^{1,1}\left(X^{\prime}=0\right)$ with increasing solids content. Orange curve calculated with equation (S1), black and red curves calculated with equation (S3). The parameters of the curves shown are freely chosen. It is demonstrated that the use of equation (S1) can lead to considerable deviations from the literature value of $k_{\mathrm{t}}{ }^{1,1}$. Furthermore, it is shown that for a low $P_{2}$ and a high $P_{3}$ value, $P_{1}$ hardly influences the shape of the curve. 


\section{Automated parameter search}

The automated parameter search is executed by a Metropolis-Hasting algorithm. ${ }^{13,14}$ The Python code used is illustrated in Figure S7 and explained below. The algorithm implemented is based on two classes: fit and model.

1. The initial values (initValue) needed for the first loop/cycle are stored in the vector fit.init. Additionally, the vector contains the associated lower and upper limits (minValue; maxValue, respectively) and the parameter relSigma (0.05) that controls the parameter variation (mutation).

2. The parameter optimization starts in the model class with the values defined in initValue (currentValues).

3. model.setValues(): transfer of the currentValues into the kinetic model of the 6 experiments $(\# \mathrm{a}-\# \mathrm{f})$

4. model.run(): simultaneous start of the simulation of all experiments with their individual recipe

5. model.wait(): delay of the next step until all simulations are finished (synchronization)

6. model.diff2(): comparison of the 6 simulations with the corresponding experimental solids contents.

7. fit.accept(): accept or discard the current parameter set. 4 cases may occur:

(I) first cycle,

(II) $\operatorname{diff}_{1}^{2}<\operatorname{diff}_{0}^{2}$,

(III) $\operatorname{diff}_{0}{ }^{2} / \operatorname{diff}_{1}^{2}>$ random number $r(0 \leq r \leq 1)$ and

(IV) $\operatorname{diff} 0^{2} / \operatorname{diff}_{1}^{2}<$ random number $r(0 \leq r \leq 1)$.

Cases (I) - (III): currentValues are accepted and $\operatorname{diff}_{0}{ }^{2}$ is set equal to $\operatorname{diff}_{1}{ }^{2}$.

Case (IV) currentValues are discarded, $\operatorname{diff}_{0}{ }^{2}$ as reference remains unchanged, last record is reused as currentValue.

8. fit.mutation(): Generation of a new parameter set by mutation considering the lower and upper bounds; The width is determined using a Gaussian density distribution of the standard deviation relSigma $*($ maxValue - minValue $) \rightarrow$ new currentValues

9. New optimization cycle starts at step 3 model.setValues() 


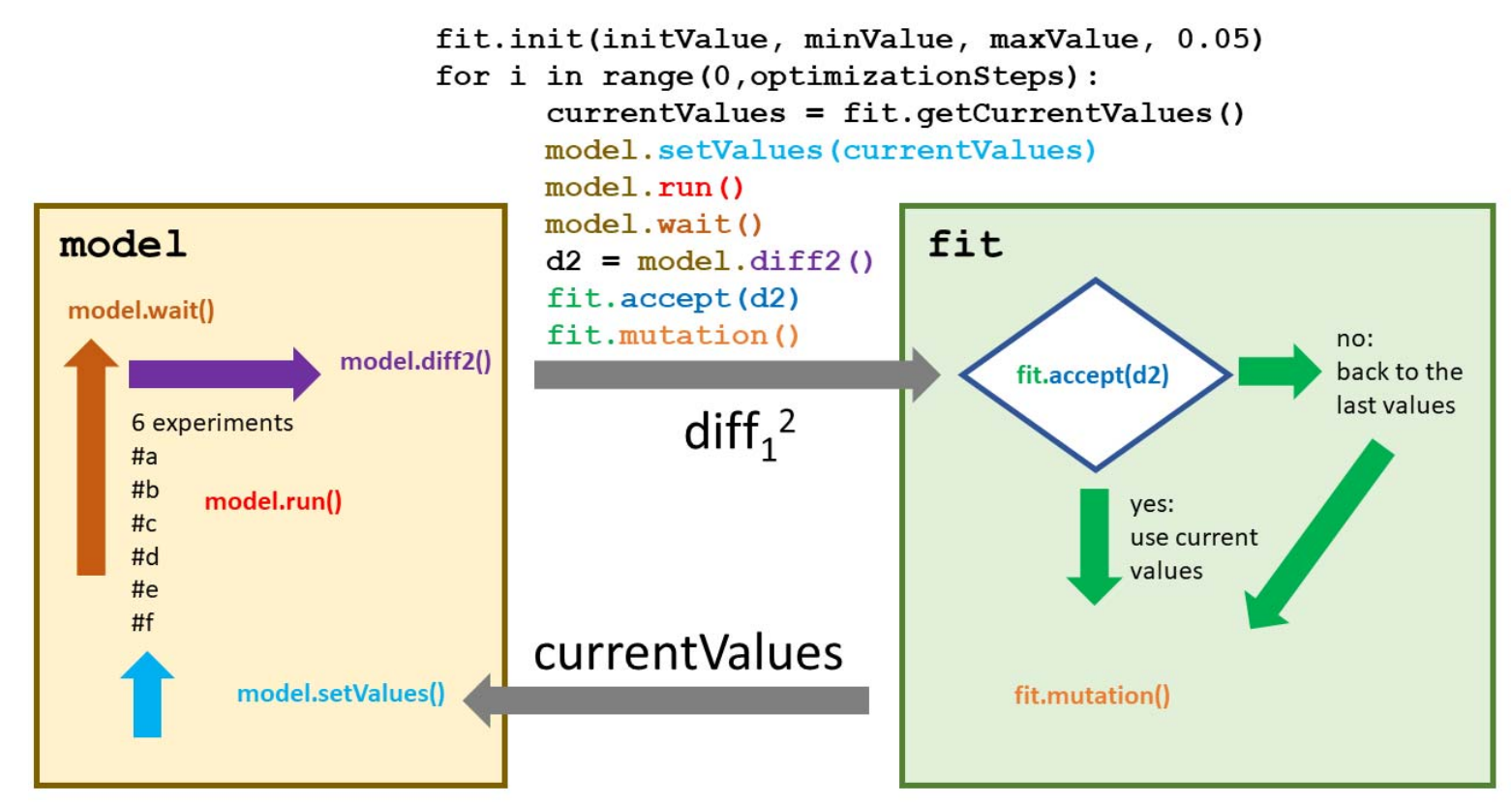

Figure S7: Scheme of the automated parameter search. The search is organized in the model class (left) and the fit class (right). The current values of the $k$ model is transferred to the kinetic model and the simulations are executed simultaneously and parallelized in the model class. In the fit class the simulations are compared with the last ones to decide if the values found are accepted or discarded. For further information please refer to the text. 


\section{Molar mass distributions}

The molar mass distributions of experiments \#a - \#f are shown in Figure S8. The molar mass distribution of experiment $\# \mathrm{~b}$ is omitted, because of discrepancies in the time allocation.
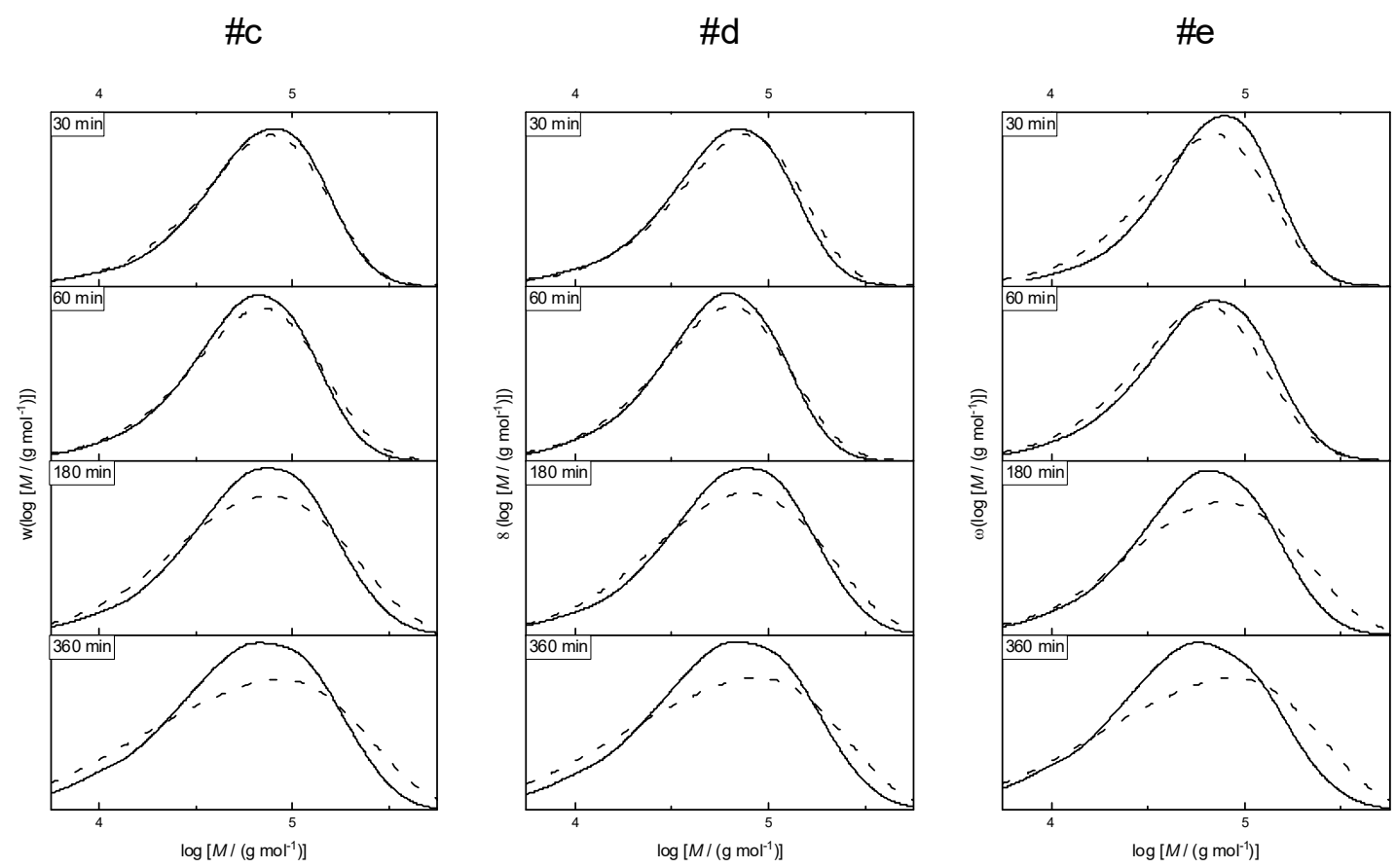

Figure S8: Molar mass distributions of the recipes \#c, \#d and \#e. Solid curves: experimental data; dashed lines: simulated data. 
Molar mass averages and dispersities

Table S2: Experimental and simulated molar mass averages and dispersities of recipe \#a.

\begin{tabular}{|c|c|c|c|c|c|c|}
\hline \multirow{2}{*}{$\begin{array}{c}\text { time } \\
\text { min }\end{array}$} & \multicolumn{3}{|c|}{ experiment } & \multicolumn{3}{c|}{ simulation } \\
\cline { 2 - 6 } & $\begin{array}{c}M_{\mathrm{n}} / \\
\mathrm{g} \mathrm{mol}^{-1)}\end{array}$ & $\begin{array}{c}M_{\mathrm{w}} / \\
\left(\mathrm{g} \mathrm{mol}^{-1}\right)\end{array}$ & $Ð$ & $\begin{array}{c}M_{\mathrm{n}} / \\
\left(\mathrm{g} \mathrm{mol}^{-1}\right)\end{array}$ & $\begin{array}{c}M_{\mathrm{w}} / \\
\left(\mathrm{g} \mathrm{mol}^{-1}\right)\end{array}$ & $Ð$ \\
\hline 30 & 56400 & 95600 & 1.69 & 46900 & 96900 & 2.07 \\
\hline 60 & 51900 & 88000 & 1.70 & 41900 & 91700 & 2.19 \\
\hline 90 & 49600 & 91500 & 1.84 & 41500 & 96300 & 2.32 \\
\hline 120 & 50800 & 94600 & 1.86 & 39900 & 101000 & 2.52 \\
\hline 150 & 48300 & 94800 & 1.96 & 36700 & 103000 & 2.81 \\
\hline 180 & 47200 & 93700 & 1.98 & 32300 & 104000 & 3.21 \\
\hline 210 & 41000 & 93500 & 2.28 & 27800 & 104000 & 3.73 \\
\hline 240 & 39100 & 88300 & 2.26 & 24000 & 103000 & 4.29 \\
\hline 270 & 36600 & 87800 & 2.40 & 20100 & 102000 & 5.08 \\
\hline 300 & 32100 & 89900 & 2.80 & 17200 & 102000 & 5.93 \\
\hline 330 & 33100 & 86900 & 2.63 & 15400 & 102000 & 6.61 \\
\hline 360 & 33300 & 86100 & 2.58 & 14500 & 102000 & 7.01 \\
\hline
\end{tabular}

Table S3: Experimental and simulated molar mass averages and dispersities of recipe \#b.

\begin{tabular}{|c|c|c|c|c|c|c|}
\hline \multirow{2}{*}{$\begin{array}{c}\text { time } \\
\min \end{array}$} & \multicolumn{3}{|c|}{ experiment } & \multicolumn{3}{c|}{ simulation } \\
\cline { 2 - 7 } & $\begin{array}{c}M_{\mathrm{n}} / \\
\left(\mathrm{g} \mathrm{mol}^{-1}\right)\end{array}$ & $\begin{array}{c}M_{\mathrm{w}} / \\
\left(\mathrm{g} \mathrm{mol}^{-1}\right)\end{array}$ & $Ð$ & $\begin{array}{c}M_{\mathrm{n}} / \\
\left(\mathrm{g} \mathrm{mol}^{-1}\right)\end{array}$ & $\begin{array}{c}M_{\mathrm{w}} / \\
\left(\mathrm{g} \mathrm{mol}^{-1}\right)\end{array}$ & $Ð$ \\
\hline 30 & 48700 & 87200 & 1.79 & 42600 & 87900 & 2.06 \\
\hline 60 & 41600 & 77200 & 1.86 & 38200 & 83000 & 2.17 \\
\hline 120 & 38800 & 84400 & 2.18 & 37600 & 93300 & 2.48 \\
\hline 180 & 39600 & 77000 & 1.95 & 30500 & 96100 & 3.15 \\
\hline 240 & 27400 & 75700 & 2.77 & 23200 & 95300 & 4.11 \\
\hline 300 & 30700 & 71300 & 2.32 & 16900 & 94400 & 5.58 \\
\hline 360 & 28500 & 69400 & 2.43 & 14000 & 94200 & 6.71 \\
\hline
\end{tabular}


Table S4: Experimental and simulated molar mass averages and dispersities of recipe \#c.

\begin{tabular}{|c|c|c|c|c|c|c|}
\hline \multirow{2}{*}{$\begin{array}{c}\text { time } / \\
\text { min }\end{array}$} & \multicolumn{3}{|c|}{ experiment } & \multicolumn{3}{c|}{ simulation } \\
\cline { 2 - 7 }$\left(\mathrm{g} \mathrm{mol}_{\mathrm{n}}^{-1}\right)$ & $\begin{array}{c}M_{\mathrm{w}} / \\
\left(\mathrm{g} \mathrm{mol}^{-1}\right)\end{array}$ & $Ð$ & $\begin{array}{c}M_{\mathrm{n}} / \\
\left(\mathrm{g} \mathrm{mol}^{-1}\right)\end{array}$ & $\begin{array}{c}M_{\mathrm{w}} / \\
\left(\mathrm{g} \mathrm{mol}^{-1}\right)\end{array}$ & $Ð$ \\
\hline 30 & 44500 & 81800 & 1.84 & 39200 & 80700 & 2.06 \\
\hline 60 & 39700 & 72100 & 1.82 & 35200 & 76100 & 2.16 \\
\hline 120 & 44000 & 87100 & 1.98 & 36500 & 88800 & 2.43 \\
\hline 180 & 38500 & 86000 & 2.24 & 31800 & 94300 & 2.96 \\
\hline 240 & 36600 & 84800 & 2.32 & 24200 & 94700 & 3.92 \\
\hline 300 & 33000 & 84100 & 2.55 & 17300 & 94000 & 5.42 \\
\hline 360 & 31900 & 81300 & 2.55 & 14500 & 93800 & 6.47 \\
\hline
\end{tabular}

Table S5: Experimental and simulated molar mass averages and dispersities of recipe \#d.

\begin{tabular}{|c|c|c|c|c|c|c|}
\hline \multirow{2}{*}{$\begin{array}{c}\text { time } \\
\min \end{array}$} & \multicolumn{3}{|c|}{ experiment } & \multicolumn{3}{c|}{ simulation } \\
\cline { 2 - 7 } & $\begin{array}{c}M_{\mathrm{n}} / \\
\left(\mathrm{g} \mathrm{mol}^{-1}\right)\end{array}$ & $\begin{array}{c}M_{\mathrm{w}} / \\
\left(\mathrm{g} \mathrm{mol}^{-1}\right)\end{array}$ & $Ð$ & $\begin{array}{c}M_{\mathrm{n}} / \\
\left(\mathrm{g} \mathrm{mol}^{-1}\right)\end{array}$ & $\begin{array}{c}M_{\mathrm{w}} / \\
\left(\mathrm{g} \mathrm{mol}^{-1}\right)\end{array}$ & $Ð$ \\
\hline 30 & 49900 & 80700 & 1.62 & 38600 & 79200 & 2.05 \\
\hline 60 & 41600 & 75600 & 1.82 & 34900 & 74700 & 2.14 \\
\hline 120 & 39800 & 76800 & 1.93 & 34600 & 82400 & 2.38 \\
\hline 180 & 39000 & 76700 & 1.97 & 29100 & 84000 & 2.89 \\
\hline 240 & 34500 & 77800 & 2.25 & 22800 & 82900 & 3.64 \\
\hline 300 & 31600 & 71700 & 2.27 & 16700 & 81800 & 4.89 \\
\hline 360 & 26500 & 71700 & 2.70 & 13600 & 81600 & 6.02 \\
\hline
\end{tabular}


Table S6: Experimental and simulated molar mass averages and dispersities of recipe \#e.

\begin{tabular}{|c|c|c|c|c|c|c|}
\hline \multirow{2}{*}{$\begin{array}{c}\text { time } / \\
\min \end{array}$} & \multicolumn{3}{|c|}{ experiment } & \multicolumn{3}{c|}{ simulation } \\
\cline { 2 - 7 } & $\begin{array}{c}M_{\mathrm{n}} / \\
\left(\mathrm{mol}^{-1}\right)\end{array}$ & $\begin{array}{c}M_{\mathrm{w}} / \\
\left(\mathrm{g} \mathrm{mol}^{-1}\right)\end{array}$ & $Ð$ & $\begin{array}{c}M_{\mathrm{n}} / \\
\left(\mathrm{g} \mathrm{mol}^{-1}\right)\end{array}$ & $\begin{array}{c}M_{\mathrm{w}} / \\
\left(\mathrm{g} \mathrm{mol}^{-1}\right)\end{array}$ & $Ð$ \\
\hline 30 & 39900 & 72900 & 1.83 & 34800 & 71500 & 2.05 \\
\hline 60 & 37600 & 66100 & 1.76 & 31700 & 67900 & 2.14 \\
\hline 120 & 41800 & 83300 & 1.99 & 36200 & 85600 & 2.37 \\
\hline 180 & 42200 & 87800 & 2.08 & 32500 & 93300 & 2.87 \\
\hline 240 & 37200 & 87200 & 2.34 & 24800 & 94200 & 3.8 \\
\hline 300 & 30800 & 86300 & 2.80 & 17700 & 93600 & 5.3 \\
\hline 360 & 32900 & 84300 & 2.56 & 14700 & 93400 & 6.37 \\
\hline
\end{tabular}

Table S7: Experimental and simulated molar mass averages and dispersities of recipe \#f.

\begin{tabular}{|c|c|c|c|c|c|c|}
\hline \multirow{2}{*}{$\begin{array}{c}\text { time } / \\
\min \end{array}$} & \multicolumn{3}{|c|}{ experiment } & \multicolumn{3}{c|}{ simulation } \\
\cline { 2 - 7 } & $\begin{array}{c}M_{\mathrm{n}} / \\
\left(\mathrm{g} \mathrm{mol}^{-1}\right)\end{array}$ & $\begin{array}{c}M_{\mathrm{w}} / \\
\left(\mathrm{g} \mathrm{mol}^{-1}\right)\end{array}$ & $Ð$ & $\begin{array}{c}M_{\mathrm{n}} / \\
\left(\mathrm{g} \mathrm{mol}^{-1}\right)\end{array}$ & $\begin{array}{c}M_{\mathrm{w}} / \\
\left(\mathrm{g} \mathrm{mol}^{-1}\right)\end{array}$ & $Ð$ \\
\hline 30 & 38100 & 65900 & 1.73 & 31500 & 64500 & 2.05 \\
\hline 60 & 32500 & 59200 & 1.82 & 28800 & 61400 & 2.13 \\
\hline 120 & 43600 & 90500 & 2.08 & 34200 & 80700 & 2.36 \\
\hline 180 & 46200 & 96300 & 2.09 & 31300 & 88500 & 2.83 \\
\hline 240 & 35200 & 85200 & 2.42 & 23900 & 89500 & 3.75 \\
\hline 300 & 35300 & 85400 & 2.42 & 17300 & 89000 & 5.14 \\
\hline 360 & 29300 & 85800 & 2.93 & 14400 & 88900 & 6.17 \\
\hline
\end{tabular}

\section{References}

(1) Barudio, I.; Févotte, G.; McKenna, T. F. L. Density data for copolymer systems: butyl acrylate/vinyl acetate homo- and copolymerization in ethyl acetate. European Polymer Journal 1999, 35 (5), 775-780. DOI: 10.1016/S0014-3057(98)00070-6. 
(2) DDBST GmbH. Liquid Density Calcualtion by DIPPR105 Equation (Methanol). http:// ddbonline.ddbst.com/DIPPR105DensityCalculation/DIPPR105CalculationCGI.exe?component= Methanol\&tunit $=$ K\&punit $=\mathrm{kg} \% 2 \mathrm{Fm} 3 \&$ TemperaturesEdit $=\&$ calculate $=$ Calculate $($ accessed $2021-$ 06-09).

(3) Akzo Nobel. Initiators:Initiators for High Polymers. http://www.neochemical.kz/File/Akzo_ Data_110407-Initiators_for_High_Polymers.pdf(accessed 2021-03-09).

(4) Nozakura, S.-I.; Morishima, Y.; Murahashi, S. Long branching in poly(vinyl acetate) and poly(vinyl alcohol). III. Kinetic study of the branching reaction in the radical polymerization of vinyl acetate. J. Polym. Sci. A-1 Polym. Chem. 1972, 10 (10), 2853-2866. DOI: 10.1002/pol.1972.170101004.

(5) Clarke, J. T.; Howard, R. O.; Stockmayer, W. H. Chain Transfer in Vinyl Acetate Polymerization. Macromol. Chem. Phys. 1961, 44 (1), 427-447. DOI: 10.1002/macp.1961.020440136.

(6) Graessley, W. W.; Hartung, R. D.; Uy, W. C. Studies of branching in polyvinyl acetate. J. Polym. Sci. A-2 Polym. Phys. 1969, 7 (11), 1919-1935. DOI: 10.1002/pol.1969.160071107.

(7) Hutchinson, R. A.; Richards, J. R.; Aronson, M. T. Determination of Propagation Rate Coefficients by Pulsed-Laser Polymerization for Systems with Rapid Chain Growth: Vinyl Acetate. Macromolecules 1994, 27 (16), 4530-4537. DOI: 10.1021/ma00094a016.

(8) McKenna, T. F. L.; Villanueva, A. Effect of solvent on the rate constants in solution polymerization. Part II. Vinyl acetate. J. Polym. Sci. A Polym. Chem. 1999, 37 (5), 589-601. DOI: 10.1002/(SICI)1099-0518(19990301)37:5<589::AID-POLA8>3.0.CO;2-1.

(9) Okaya, T.; Kikuchi, K.; Suzuki, A.; Ikeda, N. Dispersion polymerization of vinyl acetate in a mixture of ethanol and water. Polym. Int. 2005, 54 (1), 143-148. DOI: 10.1002/pi.1658.

(10) Schulz, V. G. V.; Roberts-Nowakowska, L. Über die Temperaturabhängigkeit einiger Übertragungskonstanten der radikalischen Polymerisation von Vinylacetat:Über die Verzweigung des Polyvinylacetats, IV. Makromol. Chem. 1964, 80 (1), 36-43. DOI: 10.1002/macp.1964.020800104.

(11) Tobita, H. A simulation model for long-chain branching in vinyl acetate polymerization: 2. Continuous polymerization in a stirred tank reactor. J. Polym. Sci. B Polym. Phys. 1994, 32 (5), 911-919. DOI: 10.1002/polb.1994.090320514.

(12) Wheeler, O. L.; Lavin, E.; Crozier, R. N. Branching mechanisms in the polymerization of vinyl acetate. J. Polym. Sci. 1952, 9 (2), 157-169. DOI: 10.1002/pol.1952.120090204. 
(13) Metropolis, N.; Rosenbluth, A. W.; Rosenbluth, M. N.; Teller, A. H.; Teller, E. Equation of State Calculations by Fast Computing Machines. J. Chem. Phys. 1953, 21 (6), 1087-1092. DOI: 10.1063/1.1699114.

(14) Hastings, W. K. Monte Carlo sampling methods using Markov chains and their applications. Biometrika 1970, 57 (1), 97-109. DOI: 10.1093/biomet/57.1.97. 